\title{
Micro-invertebrates conservation: forgotten biodiversity
}

\author{
Filipe Vicente
}

Received: 26 April 2010/Accepted: 13 July 2010/Published online: 23 July 2010

(C) Springer Science+Business Media B.V. 2010

\begin{abstract}
The concern about the preservation of biodiversity is due, in part, to a great level of media coverage granted in the last few years to global warming and consequential climatic changes. However, there are still considerably large gaps in scientific knowledge regarding the ecological status of many species, which results in an absence of conservation strategy for most of Earth's biodiversity in need of it. The extinction of many animal and plant species can have catastrophic consequences on the ecosystems' balance and also in human well-being, resultant from the break of ecological services. To exemplify how a specific group of microscopic animals can be endangered, I have analyzed the case of the phylum Tardigrada. Tardigrades are microscopic animals that inhabit most environments: terrestrial, freshwater and marine. Even though many species are widespread and the terrestrial ones granted with cryptobiotic skills, they are adapted to each habitat type and, additionally, to local environmental patterns. This means that these tiny metazoans can be under significant environmental pressure in the various habitat types they are found in. The potential need of protective and compensatory measures aiming for appropriate conservation of these life forms is discussed, as is the need of studying for their objective elaboration.
\end{abstract}

Keywords Biodiversity conservation - Conservation status · Micro-invertebrates · Tardigrada $\cdot$ Preventive and protective measures

Biodiversity conservation has been a worldwide issue in government agendas at least since the United Nations' Earth Summit held in Rio de Janeiro, Brazil, in 1992, where world leaders agreed on a common strategy for "sustainable development". The key pact achieved at the Summit resulted in the Convention on Biological Diversity, a document which stresses conservation of biological diversity as a global goal, as well as its

This work was partially presented at the 11th International Symposium on Tardigrada held in Tübingen, Germany, August 3-6, 2009.

F. Vicente $(\bowtie)$

Centre for Environmental Biology and Department of Animal Biology, Faculty of Sciences, University of Lisbon, Campo Grande C2, 1749-016 Lisbon, Portugal

e-mail: fjvicente@fc.ul.pt 
sustainable use and the sharing of benefits arising from the exploration of genetic resources (United Nations 1993).

The European Community has ever since been looking to be in the lead of friendly biodiversity policy-making. Examples of such concern are the Natura 2000 Network of protected areas, LIFE projects and management plans as financial instruments supporting nature conservation projects. The most relevant of the latest political endeavors in this field was known as Countdown 2010, an agreement achieved in 2001 by EU governments towards sustaining biodiversity loss and recovering natural habitats by 2010 , which around 130 other world leaders joined in 2002.

Meritorious as these efforts are, there are still great gaps in knowledge regarding poorly known taxonomic groups such as invertebrates, plants, tropical biota and all aquatic and subterranean habitats (Millennium Ecosystem Assessment 2005).

Lévêque et al. (2005) estimated that there are around 100,000 known freshwater animal species today, half of which are insects. However, many freshwater biodiversity assessment studies tend to focus on better-known groups such as fish and/or on endemic or keystone species. Also, they claim, official species richness indexes should be severely underestimated in lesser studied groups, such as protozoans, annelids or nematodes. Concerning the Protozoa, for instance, much of our knowledge of the group's biodiversity is tightly linked to clinical disease in vertebrates, mainly mammals (Adlard and O'Donoghue 1998). There is, however, a whole new world of diversity to be unveiled in the Protozoa alone, regarding those associated with invertebrates (i.e., Vicente et al. 2008) as well as all other free living species.

The IUCN's Red List of Threatened Species includes 44,838 species with assessed conservation statuses in its 2008 update (Vié et al. 2009). This number has been increasing each year and undoubtedly reflects the work of many, yet it still only represents $2.73 \%$ of all described species to date. Moreover, a quick analysis allows for a view of really how biased these assessments are towards some taxonomic groups. Considering the better studied ones, mammals and birds, $100 \%$ of the currently described species have been evaluated for their conservation statuses and, out of these, $21 \%$ out of 5,488 mammal species and $12 \%$ out of 9,990 bird species are considered to be endangered.

Turning our attention to one of the lesser studied groups, we see that only $0.13 \%$ out of all the described insect species have an evaluated status, $50 \%$ of which are endangered. This means that half of the few insect species whose conservation statuses have been assessed were classified as threatened, yet extremely few out of the 950,000 calculated species known to science have been graced with conservational study. Let me highlight that this last number does not include an estimate of the insect species that are yet to be described (surely many more than birds or mammals), which means that considering insects alone, the actual number of threatened species could easily surpass that of the sum of all existing vertebrates. A similar scenario is shared by the rest of invertebrates, plants, algae, lichens and mushrooms: very few known species have been evaluated for their threatened statuses, with few exceptions. Therefore, it appears necessary to enrich the Red List of Threatened Species with many invertebrate species endemic and/or living in specific habitats easily endangered (caves, small lakes, small rivers).

Additionally, I think that we still take biodiversity conservation under a prejudice of scale, neglecting living organisms to an extensively greater degree the smaller they get, even when knowledge is available. Stork et al. (2008) show evidence of this problem, studying canopy beetles. If this is true for small macroscopic animals, the more truthful it becomes for microscopic ones. In other words, when we talk about preserving biodiversity, we should not disregard microscopic organisms since their existence is of a crucial nature for the maintenance of a sustainable balance in all of Earth's ecosystems. 
In order to illustrate how a specific group of microscopic organisms can be endangered, let's consider the Tardigrada phylum. Tardigrades, commonly known as water bears, are microscopic metazoans, usually much less than $1 \mathrm{~mm}$ in length that can be found in most environments, terrestrial, freshwater and marine.

On terrestrial environments, their preferential living substrates are mosses, lichens and leaf litter. Regardless of their ability to disperse with ease and high abundance, tardigrades are habitat-dependent in a similar way to larger animals (Guil et al. 2009). Many limnoterrestrial species are ecologically specialized and able to survive only in particular microenvironmental conditions. This is particularly true for parthenogenetic taxa with low individual variability (Pilato 1979; Pilato and Binda 2001), and recent studies demonstrate that the number of endemic species is higher than traditionally believed (Pilato 1979; Pilato and Binda 2001). Hence, the destruction of these micro-habitats, due to e.g. the humanization of natural areas, causes obvious reduction of population effectives and may cause similar results in the phylum's biodiversity, with the extinction of some species even before they were known to science. Other causes behind habitat reduction are, for instance, air pollution, as this is known to inhibit lichen growth (Jovan 2008). Moreover, pollution can directly cause a reduction in tardigrade species and specimen number (Vargha et al. 2002). A contemporary example of the effect air pollution has on these animals comes from China, were acidic rain appears to be behind the disappearing of tardigrades from most areas where air pollution is stronger (Miller, pers. comm.).

Forest fires are another obvious menace yet, ironically, some fire prevention procedures may end up being an even bigger one. Quartau (2008) pinpoints how mandatory forestall vegetation clearance methodologies have been carried out in Portugal and how much they represent a serious threat to biodiversity. These methods involve the complete removal of all potential burning materials, including bushes, herbaceous plants and grasses, pines, branches and leaf litter. Since these organic materials will usually be burnt for energy production, the outcome is clearly catastrophic for animal groups inhabiting those substrates, including ground fauna, entomofauna and other macro and micro invertebrates, as well as for all the inferior plants that are removed. Considering just the fauna, mass extinctions can take place, resulting in the loss of an unprecedented number of endemic species, before they were even known to science (Quartau 2008). Additionally, we should also consider the ecological consequences both for humankind, with the breaking of ecological services, as well as for all other fauna to some extent dependent on the lost biodiversity. Among such ecological services are the maintenance of the nutrient cycle and soil fertility, the production of food, fuel and medicines, the regulation of hydric resources, air and climate (Commission of the European Communities 2006), and the control of pests or diseases (Price 1987). These roles played by the natural systems highlight how important biodiversity is for sustainable development and general human well-being.

Returning to the example of tardigrades, global warming poses the greatest menace to the freshwater species. Rebecchi et al. (2009) recently demonstrated that the limnic species Borealibius zetlandicus is intolerant to desiccation. In the case of this limitation being shared by other limnic species, they can become extinct in temperate areas such as Southern Europe, where future higher temperatures may turn permanent rivers, ponds and lagoons into temporary ones. The eventual verification that strictly freshwater species are desiccation intolerant should not come as a surprise since the ability to undergo anhydrobiosis is an adaptation of the terrestrial tardigrades and most marine tardigrades are known to be desiccation intolerant (Ramazzotti and Maucci 1983).

That does not mean, however, that the terrestrial species cannot be endangered by the climatic changes, since their desiccation tolerances have been proved to differ from one 
climatic region to another (Horikawa and Higashi 2004), and local adaptation to current climatic patterns is a decisive factor in the current geographic distribution of tardigrades (Faurby et al. 2008; Pilato 1979; Pilato and Binda 2001).

In marine environments, tardigrades can be found anywhere, from deep sea floors to beaches, dwelling in the sediments. However being one of the main groups comprising meiofauna, their ecological importance is still poorly understood. On beaches, species distribution follows a tide influenced gradient (Kinchin 1992; Morgan and Lampard 1986). Considering the expected rising of the sea level as yet another consequence of global warming, the species distribution pattern can be totally disrupted along worldwide shores, wherever beaches become permanently flooded. This could mean the loss of immense habitat areas that are vital for the survival of this and other faunal groups. Adrianov (2004) estimates meiofauna to be composed of 20-30 million species, so it is not difficult to imagine how a swift change in the sea level would affect many animal species inhabiting the current tidal zone. Aquatic pollution from all types of sources may also have an impact on marine tardigrades, but no studies exist hitherto on this subject. Pollution has, however, been proved to negatively correlate with nematode population structure in an estuarine environment (Gyedu-Ababio et al. 1999). Hence, the assumption of a negative effect from water pollution on marine tardigrades should not strike us as being too far-fetched.

Facing any of the previously referred cases of potential harm to the diversity of tardigrades, one could argue that given the great colonization capabilities these animals have, it would allow them to re-populate any given habitat, once the threat disappears. True as it may be for some ubiquitous species, it will not be so for all others that are endemic. We should also keep in mind that the event of a re-colonization does not exclude the hypothesis of considerable genetic diversity loss. Malmström et al. (2009) found that 5 years after a fire the number of tardigrades had reached $52 \%$ of those found in the unburnt area. Nevertheless, this study did not include any species identification procedures, so it is impossible to infer on how effective re-colonizations can be in restoring the original biodiversity levels. The destruction of a microhabitat to which an endemic species is uniquely linked produces a marked reduction of genetic diversity or even the extinction of that species. More studies on this matter are required, since our limited knowledge prevents us from reaching the understanding on whether or not preventive measures are required to protect micro-fauna, as well as on which they should be.

Lack of knowledge should not, however, be reason enough to prevent the taking up of protective measures, general as they may be. This is stated in the Convention on Biological Diversity (2001): “(...) where there is a threat of significant reduction or loss of biological diversity, lack of full scientific certainty should not be used as a reason for postponing measures to avoid or minimize such a threat." Increasing our understanding of biodiversity and the ecosystem's services is today a critical need and also a scientific challenge in order to perfect future political response (Commission of the European Communities 2006).

Considering the absolute inexistence of studies regarding tardigrade diversity from a conservational point of view, I believe that these animals, and others, could benefit from some preventive and compensatory measures, in order to counter-act current threats. I hereby suggest a few, divided into general and specific ones.

Generally all micro-invertebrate populations would benefit from:

(a) A reduction in all forms of environmental pollution.

(b) An immediate cutback in greenhouse-effect gas emissions, in order to prevent shortterm climatic changes. 
(c) A decrease in the current rate of habitat destruction resulting from human activities. An example of how habitat conversion for human usage could be compensated would be achieved by a more frequent adoption of what is known as "Green roofs". This architectural practice is common, for instance, in some northern European regions and consists of creating gardens or other green areas in roof tops, thus 'giving back' a certain percentage of the soil surface that was 'robbed' by the construction.

On a specific level, this particular taxon could benefit from:

(d) Forestall clearance methodologies that took micro-fauna into consideration. These would include the removal of only the strictly necessary amount of biomass from woods, roads, paths or forestall corridors. Additionally, the removed materials should not be burned or destroyed in any other way in order to preserve all the live-forms contained there. As an alternative, they could be translocated to a nearby area where the risk of fire would be inferior or virtually inexistent.

(e) Ex situ preservation projects. These could be conducted in public or private gardens or green houses and would act as genetic banks, in a similar way to the part played by zoos and aquariums today.

(f) Beaches partially or totally closed to humans. This would protect coastal/marine life from the great pressure imposed by people during summer months, and could be achieved by implementing coastal protected areas.

(g) An extension of taxonomic and biological studies. Particularly useful appears the recent genetic work: Tardigrade Barcoding Project (Schill 2009), TABAR (Guidetti et al. 2009b), TardiBASE (Blaxter 2008), Kumamushi Genome Project (Kunieda et al. 2008), MoDNA (Cesari et al. 2009; Guidetti et al. 2009a). This would not only inflate our level of knowledge but would potentially help create new lines of research where water-bears have not yet been used. It would also help draw media attention to the taxon, important leverage for a successful conservation strategy.

All of these suggestions are being made a priori and, even though some of them could prove to be somewhat correct, they would have to be refined in order to accurately provide protection for the Tardigrade biodiversity. Obviously, such perfectioning of any given conservational methodology can only arise from previous studying. These pioneer studies shall hopefully come true in a near future, for they are critically necessary not only to help us protect a vast animal taxon whose full ecological importance still eludes our understanding; but also, and more importantly, to help bring about a more generalized discussion on the conservation of all of those taxonomic groups thus far neglected.

Acknowledgments I wish to thank Professor Roberto Bertolani, University of Modena and Reggio Emilia, Italy, and Professor Artur Serrano, University of Lisbon, Portugal, for valuable comments and suggestions. I also wish to thank Dr. Timothy Bancroft-Hinchey at the Oxford School of Languages, Lisbon, for reviewing the English manuscript. This work was supported by the Fundação para a Ciência e a Tecnologia, Portugal.

\section{References}

Adlard RD, O'Donoghue PJ (1998) Perspectives on the biodiversity of parasitic protozoa in Australia. Int J Parasitol 28:776-786

Adrianov AV (2004) Current problems in marine biodiversity studies. Russ J Mar Biol 30(1):1-16

Blaxter M (2008) TardiBASE - the home of the Edinburg Tardigrade Project. http://xyala.cap.ed.ac.uk/tardi grades/tardibase.html. Accessed 26 June 2009 
Cesari M, Bertolani R, Rebecchi L, Guidetti R (2009) DNA barcoding in Tardigrada: the first case study on Macrobiotus macrocalix Bertolani \& Rebecchi 1993 (Eutardigrada, Macrobiotidae). Mol Ecol Resour 9:699-706

Commission of the European Communities (2006) Halting the loss of biodiversity by 2010 — and beyond; sustaining ecosystem services for human well-being. Commission of the European Communities, Brussels

Convention on Biological Diversity (2001) 2010 Biodiversity target. http://www.biodiv.org/2010-target/ default.asp. Accessed 15 July 2009

Faurby S, Jönson KI, Rebecchi L, Funch P (2008) Variation in anhydrobiotic survival of two eutardigrade morphospecies: a story of cryptic species and their dispersal. J Zool 275:139-145

Guidetti R, Schill R, Bertolani R, Dandekar T, Wolf M (2009a) New molecular data for tardigrade phylogeny, with the erection of Paramacrobiotus gen. nov. J Zool Syst Evol Res 47(4):315-321

Guidetti R, Rebecchi L, Bertolani R, Cesari M, Jorgensen A (2009b) Tardigrada barcoding-TABAR. http://www.barcodinglife.org. Accessed 20 October 2009

Guil N, Sánchez-Moreno S, Machordom A (2009) Local biodiversity patterns in micrometazoans: are tardigrades everywhere? Syst Biodivers 7(3):259-268

Gyedu-Ababio TK, Furstenberg JP, Baird D, Vanreusel A (1999) Nematodes as indicators of pollution: a case study from the Swartkops River system, South Africa. Hydrobiologia 397:155-169

Horikawa DD, Higashi S (2004) Desiccation tolerance of the tardigrade Milnesium tardigradum collected in Sapporo, Japan, and Bogor, Indonesia. Zool Sci 21:813-816

Jovan S (2008) Lichen bioindication of biodiversity, air quality, and climate: baseline results from monitoring in Washington, Oregon, and California. Gen. Tech. Rep. PNW-GTR-737. U.S. Department of Agriculture, Forest Service, Pacific Northwest Research Station, Portland, 115 pp

Kinchin IM (1992) An introduction to the invertebrate microfauna associated with mosses and lichens with observations from maritime lichens on the West coast of the British Isles. Microscopy 36:721-731

Kunieda T, Katayama T, Toyoda A, Horikawa D, Arakawa K, Kuwahara H, Yamaguchi A, Aizu T, Abe W (2008) Kumamushi Genome Project. http://kumamushi.org. Accessed 20 July 2009

Lévêque C, Balian EV, Martens K (2005) An assessment of animal species diversity in continental waters. Hydrobiologia 542:39-67

Malmström A, Person T, Ahlström K, Gongalsky KB, Bengtsson J (2009) Dynamics of soil meso- and macrofauna during a 5-year period after clear-cutburning in a boreal forest. Appl Soil Ecol 43:61-74

Millennium Ecosystem Assessment (2005) Ecosystems and human well-being: biodiversity synthesis. World Resources Institute, Washington, DC, $86 \mathrm{pp}$

Morgan CI, Lampard DJ (1986) Supralittoral lichens as a habitat for tardigrades. Glasg Nat 21:127-138

Pilato G (1979) Correlations between cryptobiosis and other biological characteristics in some soil animals. Boll Zool 46:319-332

Pilato G, Binda MG (2001) Biogeography and limno-terrestrial Tardigrades: are they truly incompatible binomials? Zool Anz 240:511-516

Price PW (1987) The role of natural enemies in insect populations. In: Barbosa P, Schultz JC (eds) Insect outbreaks. Academic Press, Inc, London, pp 287-312

Quartau JA (2008) Preventative fire procedures in Mediterranean woods are destroying their insect biodiversity: a plea to the EU governments. J Insect Conserv 13:267-270

Ramazzotti G, Maucci W (1983) Il phylum Tardigrada. Memorie dell'Istituto Italiano di Idrobiologia 41:1-1012

Rebecchi L, Boschini D, Cesari M, Lencioni V, Bertolani R, Guidetti R (2009) Stress response of a boreoalpine species of tardigrade, Borealibius zetlandicus (Eutardigrada, Hypsibiidae). J Limnol 68(1): 64-70

Schill R (2009) Tardigrade Barcoding Project. http://tardigradebarcoding.org. Accessed 20 July 2009

Stork NE, Grimbacher PS, Storey RI, Oberprieler RG, Reid CAM, Slipinski SA (2008) What determines whether a species of insect is described? Evidence from the study of tropical forest beetles. Insect Conserv Divers 1(2):114-119

United Nations (1993) Multilateral convention on biological diversity (with annexes): concluded at Rio de Janeiro on 5 Juno 1992. Treaty Ser 1760(30619):142-382

Vargha B, Ötvös E, Tuba Z (2002) Investigations on ecological effects of heavy metal pollution in Hungary by moss-dwelling water bears (Tardigrada) as bioindicators. Ann Agric Environ Med 9:141-146

Vicente F, Michalczyk L, Kaczmarek L, Boavida MJ (2008) Observations on Pyxidium tardigradum (Ciliophora), a protozoan living on Eutardigrada: infestation, morphology and feeding behavior. Parasitol Res 103:1323-1331

Vié J-C, Hilton-Taylor C, Stuart SN (eds) (2009) Wildlife in a changing world—an analysis of the 2008 IUCN Red List of threatened species. IUCN, Gland, $180 \mathrm{pp}$ 